استعمال النواتج الأيضية لبكتريا حامض اللاكتيك العلاجية لتثبيط

$$
\begin{aligned}
& \text { نمو عزلات مرضية معزولة من حيوانات مصابة } \\
& \text { علي حسين علي حميد صبري جثير المروزي حسن رحيم الثريفي }
\end{aligned}
$$

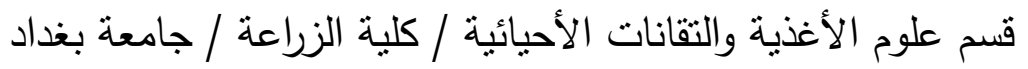

$$
\begin{aligned}
& \text { البحث مستل من رسالة ماجستير }
\end{aligned}
$$

الخلاصة

نميت ثناثة أنواع من بكتريا حامض اللاكتيك العلاجية المعزولة محلياً وهي :

و Lctobacillus reuteri (Lb. reut.) و Lactobacillus acidophilus (Lb.acid.)

MRS (Man Reqosa and Sharp) في وسطي الحليب الكامل والـ Bifidobacterium ssp. (Bif) السائلين بشكل منفرد أو خليط ثنائي (Lb.acid. + Lb.reut. + أوثلاثي (Bid. + Bif.

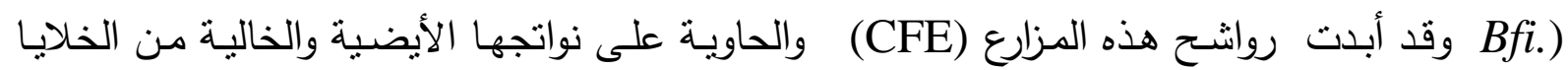

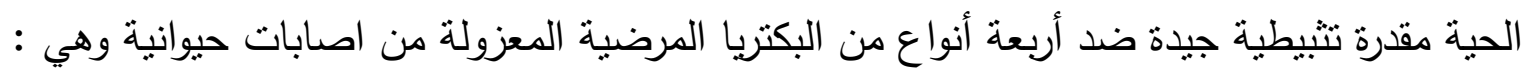
Escherichia coli, Salmonella typhimurium, Staphylococcus aureus, Proteus vulgaris وقد دلت نتائج التتبيط ضد بكتريا الـ coli إن أفضل مدة تحضين لجميع مزارع بكتريا حامض اللاكتيك

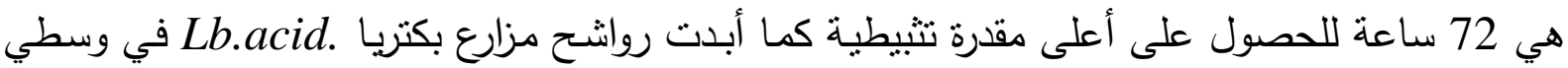

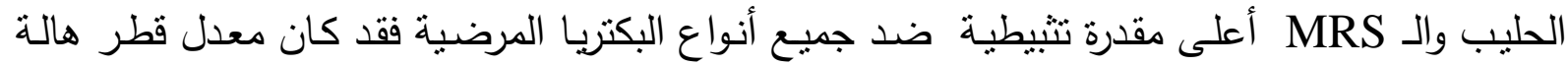
التنبط الإجمالي (14.6-15.3) لوسطي الحليب والـ MRS على التوالي كما احتفظت هذه الرواشتح

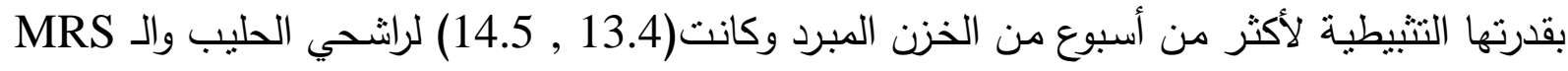

\title{
Use of metabolites of therapeutic Lactic acid bacteria to inhibit four species veterinary pathogenic bacteria
}

\author{
Ali H. A . Hamid, S.C. Abood, H.R.Al sharefe
}

Food Sci. \& Biotech. College of Agriculture University of Baghdad

\section{Summary}

This study aimed to detect metabolites inhibition activity for three therapeutic Lactic acid bacteria Lactobacillus acidophilus (Lb. acid.), Lactobacillus reuteri (Lb. reut.) and Bifidobacterium ssp. (Bif.) which were grown in whole milk and Man Reqosa and Sharp (MRS) broth as single or double (Lb. acid. + Bif.) or mixed (Lb. reut + Bif. + Lb. acid) culture Cell Free Extract (CFE) of these culture which contained their metabolites of Lactic acid bacteria (exclusion $L b$. reut.) showed good inhibition against four species of pathogenic Escherichia 
coli ; Salmonella typhimurium; Proteus volgaris and Staphylococcus aureus. inhibition activity against $E$. coli culture showed that 72 hours was the best incubation time for Lactic acid bacteria to produce more metabolite with best inhibition activity. Metabolite (CFE) of Lb. Acid culture grown in milk and MRS broth showed the best inhibition activity against all of Gram Positive and Gram negative test bacteria with over all inhibition zone diameter was 14.6 and $15.3 \mathrm{~mm}$ for milk and MRS broth supernatant respectively and this activity remained for more than one week as inhibition zone diameter were 13.4 and $14.5 \mathrm{~mm}$ for supernatant of milk and MRS respectively.

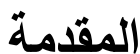

شهدت السنوات الأخيرة من القرن الماضي وبدايات القرن الحالي تطوراً واضحاً في طرق العلاج

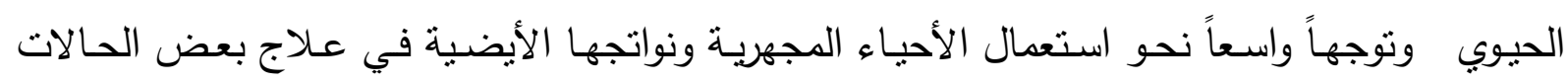

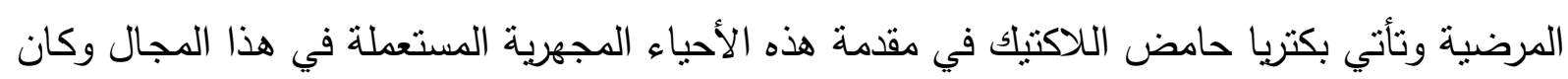

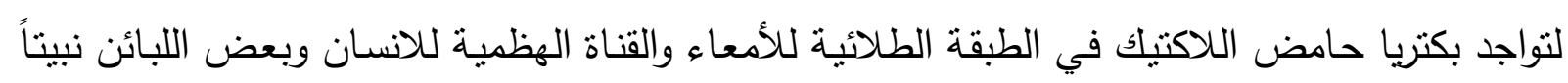

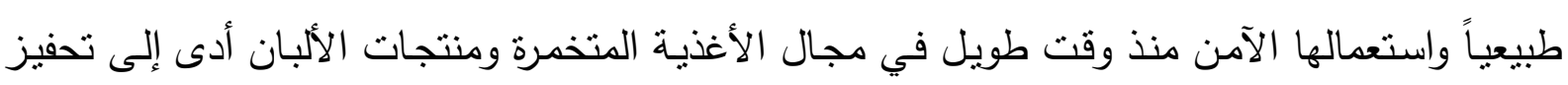

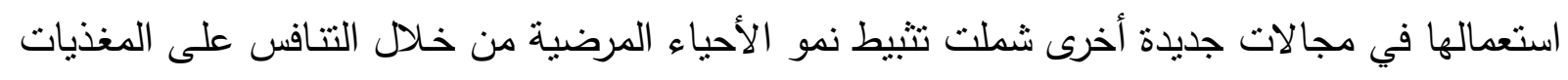
ومن خلال انتاجها للعديد من المواد الأيضية ذات الثأثير التثبيطي كالحوامض الاحئ العضوضية (لاكتيك-خليك-

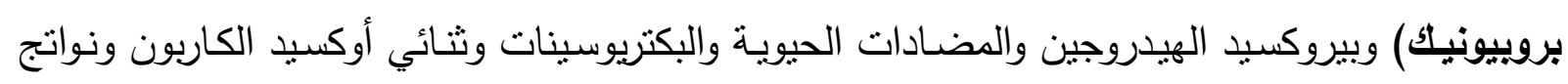

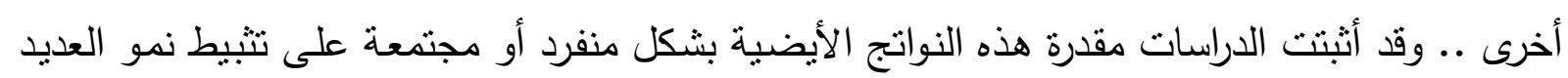

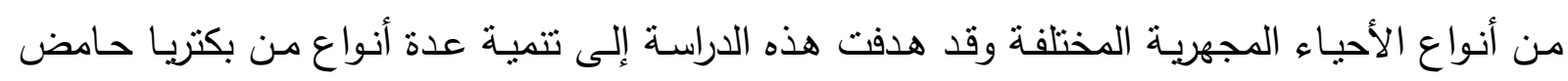

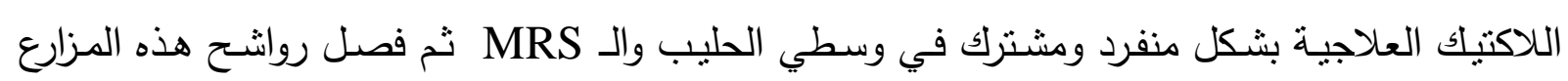
واستعمالها في حالتها السائلة في تجارب تثنيط ضد ضد البكتريا المرضية. المواد وطرائق العمل

1. العزلات البكتيرية: اختبرت ثلاثة أنواع من البكتريا العلاجية هي . Lb. reut. و و . Lb. acid.

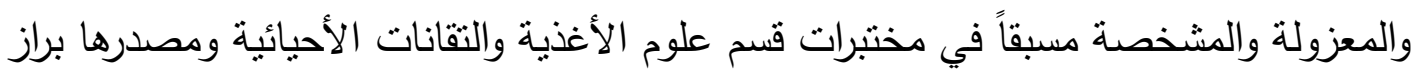

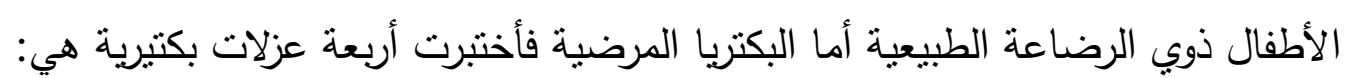
Salmonella typhimurium, Escherichia coli, Staphylococcus aureus, Proteus vulgaris من مختبرات قسم علوم الأغذية والثقانات الأحيائية ومصدرها عدة إصابات بيطرية ثم نشِيطت هذه العزلات وأجريت عليها بعض الفحوص التأكيدية. 
حُضِرَ (CFE) راشح المزرعة البكتيرية للبكتريا العلاجية والحاوي على نواتجها الأيضية

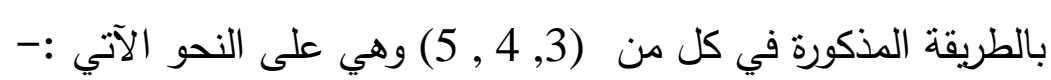

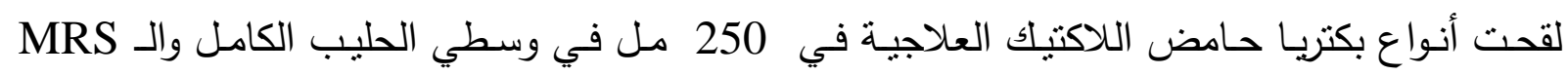

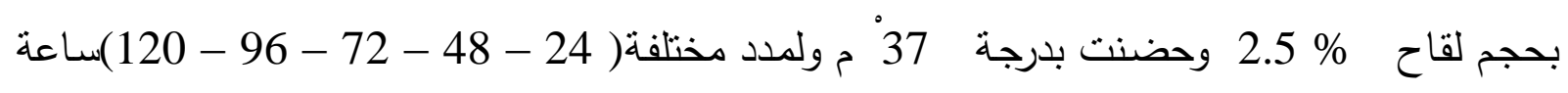
وبثلاثة مكررات ثم استعمل (CFE) لهذه المزارع في التضاد مع بكتريا استعملت معياراً لإختيار مدة الحضن الأمتل للحصول على الراشح ذو المقدرة التنبيطية الأمثل ثم اجريت

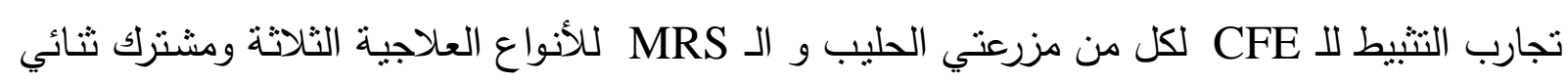
(Bfi. + Lb. acid.) وبعد اسبوع و اسبوعين من وضعه في الثلاجة , وبعد اسبوعين من وضعه بدرجة حرارة الغرفة ـ CFE

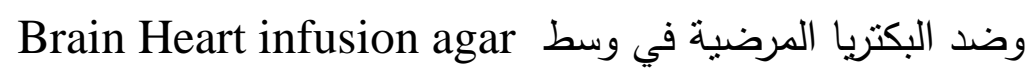

\section{النتائج}

1

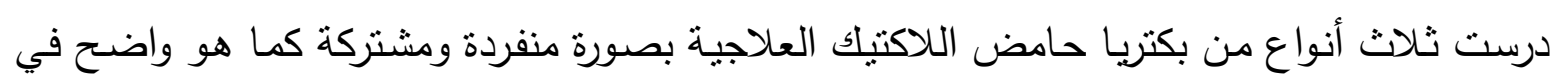

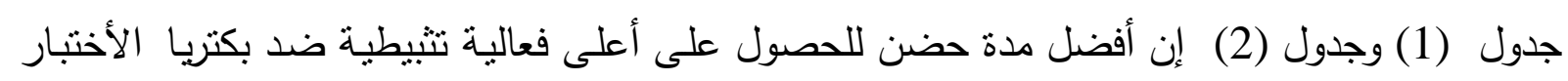
(Escherichia coli) لكل من الوسطين أي فعالية تثبيطية عند مدة حضن 24 ساعة وبدأت الفعالية التثبيطية بالظهور عند وند

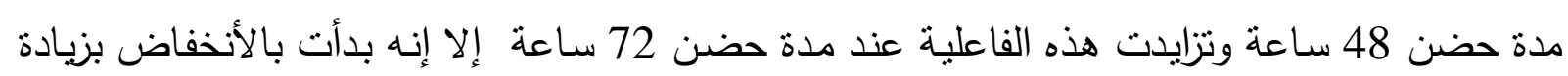
مدة الحضن باستثناء راشتح مزرعة بكتريا . Lactobacillus acid الذي يبقى محتفظاً تقريباً بفعالية

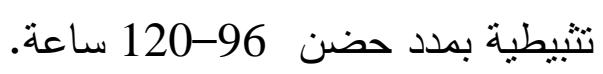


المجلة الطبية البيطرية العراقية ، المجلد 29 ، العدد 2 ، السنة 2005

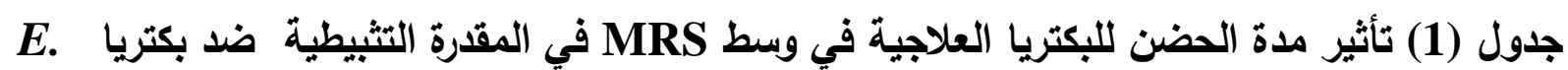
coli

\begin{tabular}{|c|c|c|c|c|c|}
\hline $\begin{array}{c}\text { ثلاثي } \\
\text { Lb. acido. + } \\
\text { Lb. reut. + Bif. } .\end{array}$ & $\begin{array}{c}\text { ثنائي } \\
\text { Bif. }+ \text { Lb. acido }\end{array}$ & Bifido. & Lb. reut. & Lb. acido. & 勇 \\
\hline 6.0 & 6.2 & 5.8 & 5.5 & 6.0 & 24 \\
\hline 12.2 & 9.6 & 7.0 & 7.2 & 9.9 & 48 \\
\hline 15.0 & 14.6 & 10.2 & 9.3 & 16.8 & 72 \\
\hline 14.2 & 14.5 & 9.0 & 8.8 & 16.8 & 96 \\
\hline 13.8 & 14.2 & 7.2 & 8.7 & 16.8 & 120 \\
\hline
\end{tabular}

قطر الحفرة 5 ملم محسوب مع النتائج

E. العول (2) تأثير مدد الحضن للبكتريا العلاجية في وسط الحليب في المقدرة التثبيطية ضد بكتريات coli

\begin{tabular}{|c|c|c|c|c|c|}
\hline $\begin{array}{c}\text { ثلاثي } \\
\text { Lb. acido. }+ \\
\text { Lb. reut. + Bif. }\end{array}$ & Bif.+ Lb. acido & Bifido. & Lb. reut. & Lb. acido. & مدة الحضن \\
\hline لا يوجد تثبيط & لا يوجد تثبيط & لا يوجد تثبيط & لا يوجد تثبيط & لا يوجد تثبيط & 24 \\
\hline 10.0 & 9.4 & 6.9 & 6.7 & 9.2 & 48 \\
\hline 13.2 & 13.6 & 9.8 & 6.9 & 16.2 & 72 \\
\hline 13.0 & 13.2 & 9.0 & 6.7 & 16.2 & 96 \\
\hline 12.0 & 13.0 & 6.8 & 6.2 & 16.1 & 120 \\
\hline
\end{tabular}

قطر الحفرة 5 ملم محسوب مع النتائج

التثبيط ضد البكتريا الاختبارية :

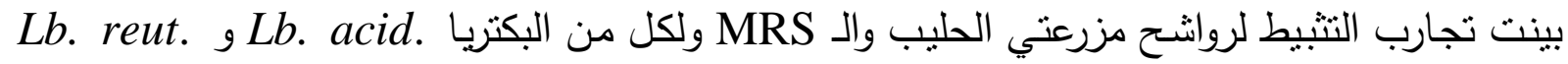

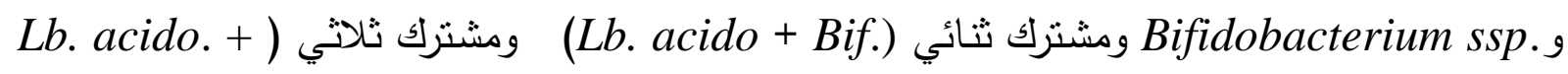
(Bifido + Lb. reut.

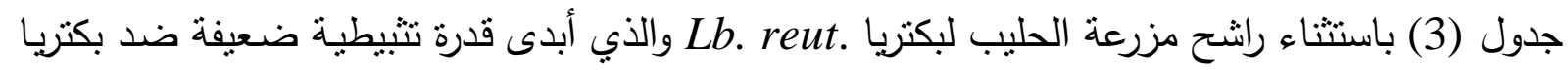
الاختبار. 
المجلة الطبية البيطرية العراقية ، المجلد 29 ، العدد 2 ، السنة 2005

جدول (3) معدلات أقطار التثبيط لرواشتح عدة أنواع من بكتريا حامض اللاكتيك العلاجية ضد 4 أنواع من بكتريا الاختبار

\begin{tabular}{|c|c|c|c|c|c|c|}
\hline \multicolumn{6}{|c|}{ معدل التبيط ( ملم ) } & \multirow[b]{3}{*}{ راشح بكتريا } \\
\hline \multicolumn{3}{|c|}{ مزرعة الحليب } & \multicolumn{3}{|c|}{ مزرعة الـ MRS مز } & \\
\hline (+ الكلي & الموجبة & الجراثليم & $\begin{array}{c}\text { الكلي } \\
\text { (+ و- }\end{array}$ & الموجبة & الجراثيم & \\
\hline 14.7 & 15 & 14.5 & 15.6 & 16.2 & 15.1 & Lb. acid. \\
\hline 7 & 7.5 & 6.5 & 9.7 & 10.5 & 8.9 & Lb. reut. \\
\hline 9.5 & 10 & 9.1 & 9.9 & 10.4 & 9.5 & Bifidobacterium \\
\hline 12.2 & 12.5 & 12 & 14.5 & 16 & 13 & Lb. acid. + Bif. \\
\hline 12.3 & 12 & 12.7 & 14.5 & 15.5 & 13.6 & Lb. acid. + Lb.reut. + Bif. \\
\hline
\end{tabular}

E.coli Sal.typhimurium Proteus vulgaris البكتريا الاختبارية السالبة لصبغة كرام هي

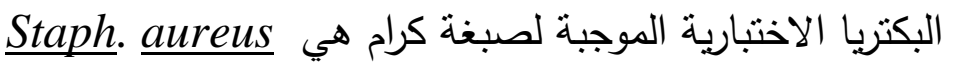

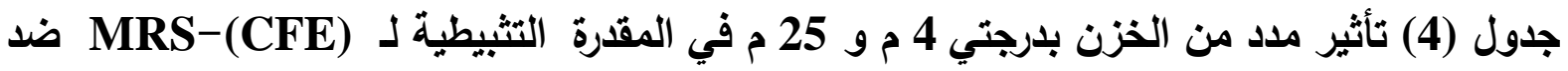

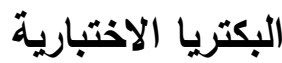

\begin{tabular}{|c|c|c|c|}
\hline بعد اسبوعين بحرارة & بعد اسبوعين بالثلاجة & $\begin{array}{c}\text { بعد اسبوع بالثالاجة } \\
4 C^{0}\end{array}$ & راشح بكتريا \\
\hline 6.6 & 7.2 & 14.5 & Lb. acid. \\
\hline لا يوجد تثبيط & 5.6 & 7.6 & Lb. reut. \\
\hline لا يوجد تثبيط & 6.1 & 6.9 & Bif. \\
\hline 5.7 & 6.5 & 10.9 & Lb.acido. + Bif. \\
\hline 5.7 & 6.5 & 10.5 & Lb.acido. + Bif. + Lb. reut. \\
\hline
\end{tabular}

* النتائج هي معدلات التثبيط ضد 4 أنواع من بكتريا الاختبار | قطر الحفرة 5 ملم محسوب مع النتائج 
المجلة الطبية البيطرية العراقية ، المجلد 29 ، العدد 2 ، السنة 2005

جدول (5) أحتفاظ ( CFE - الحليب ) بمقرته التثبيطية مع الزمن

\begin{tabular}{|c|c|c|c|}
\hline بعد اسبوعين بحرارة & بعد اسبوعين بالثلاجة 4 بع $^{0}$ & بعد اسبوع بالثلاجة $4 \mathrm{C}^{0}$ & راشح بكتريا \\
\hline 5.9 & 6.7 & 13.4 & I $h$ acid \\
\hline لا يوجد تثبيط & لا يوجد تثبيط & لا يوجد تثبيط & Lb. reut. \\
\hline لا يوجد تثبيط & لا يوجد تثبيط & 6.6 & Bif. \\
\hline لا يوجد تثبيط & 6.5 & 10.9 & Lb.acido. + Bif. \\
\hline لا يوجد تثبيط & 6.4 & 10.5 & Lb.acido. + Bif. + Lb. reut. \\
\hline
\end{tabular}

" * النتائج هي معدلات الثنيط ضد 4 أنواع من بكتريا الاختبار

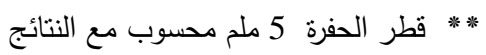

\section{المناقشة}

1- دراسة تأثير مدة الحضن في المقدرة التثيطية للبكتريا العلاجية:

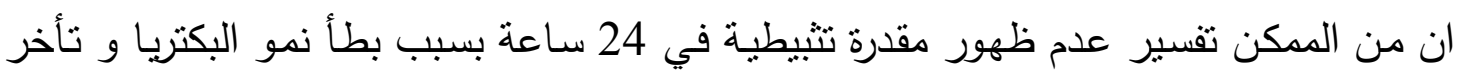

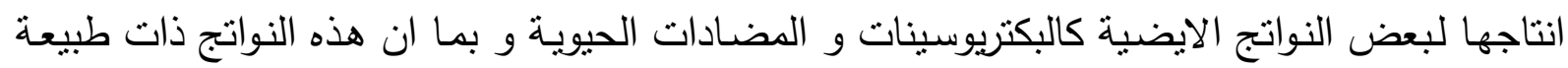
بروتينية فهي تكون عرضة لعمل الانزيمات المحللة للبروتين و الحموضة عند زيادة مدة الحضن عن 72 ساعة (6, 7) لذا فان مدة 72 ساعة هي الامتل لانتاج راشتح تثبيطي.

2- 2- التبيط ضد البكتريا الاختبارية:

بينت النتائج المقدرة الواضحة لرواشتح البكتريا العلاجية لوسطي MRS و و الحليب مـع أفضلية واضحة لبكتريا Lb.acid بمفردها ولوسطي الحليب و MRS و ذلك بسبب فعالية النواتج الايضية ذات

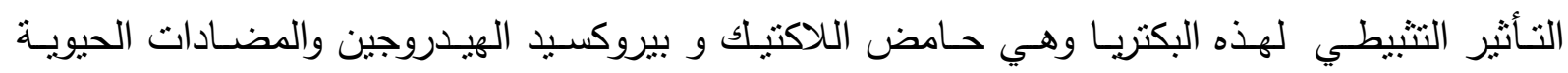
Acidolin, Acidophilin

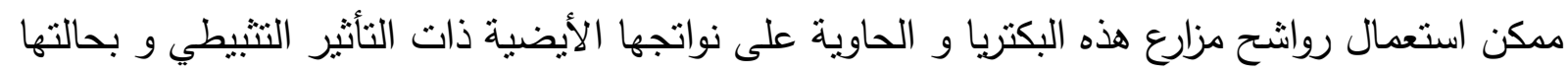

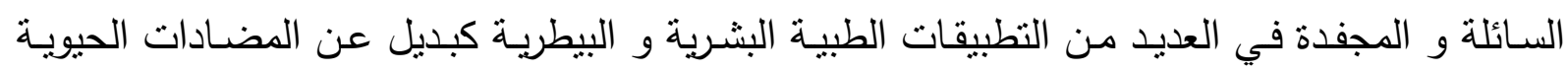

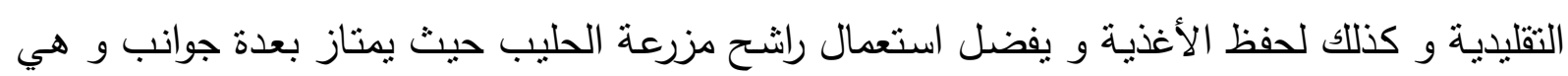

أ. الجانب الاقتصادي كون المواد الاولية اللازمـة للانتاج و هي الحليب الخام و العزلات البكتبريـة

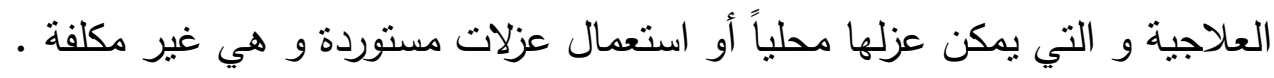

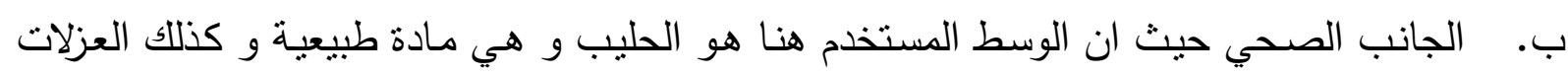

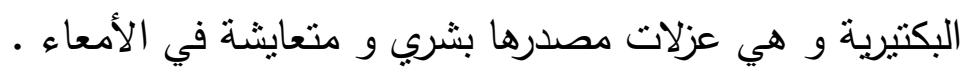


ج.الجانب التصنيعي : ففي حالة استخدام هذه الرواشح في حفظ منتجات الأغذية كالالبان مثناً حيث

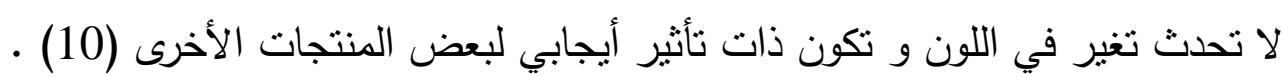

\section{References}

1. Boestroo, M. H.; Wit, J. C.; Kusters, B.J. and Robouts, F.M. (1993). Inhibition of growth of yeasts in Fermented Salad. J. Food Microbiology, 17:311-320

2. الجبوري , حسين لفتة هوير • (1996) ـ تأثثر بكتريا حامض اللاكتيك وملح الطعام على نمو

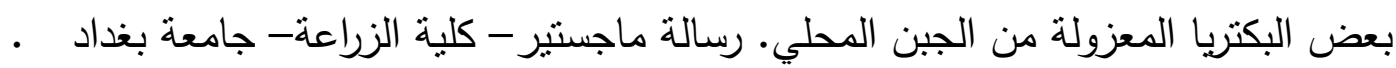

3. Roy, D.; Berger, J. and Reuter, G . (1994). Characterizations of dairy related Bifidobacterium ssp. Based on their B. galactosidase electrophoretic Patterns . J. food Microbiology , 23:55-70.

4. الثيخ ظاهر , عامر عبد الرحمن ـ (1999) دراسة مقارنة للصفات الكيميوحيوية لعزلة محلية

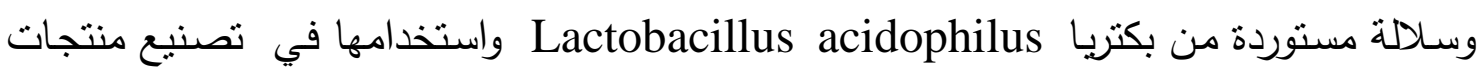
علاجية. أطروحة-دكتوراه - كلية الزراعة - جامعة بغداد.

5. نظام الدين , بهاء نظام عيسى • (2002) • تشخيص وانتقاء بكتريا الـ Bifidobacterium

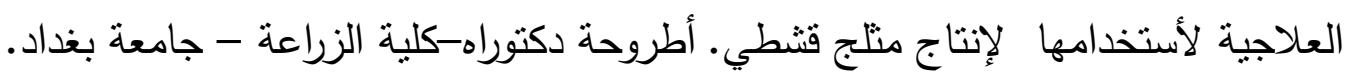

6. Ibrahim, S. snd Bezkorovainy, A. (1993). Inhibition of Escherichia coli by Bifidobacteria . J . food prot. 56:713-715 .

7. Rammelsberg, M.; Muller, E. and Radler , F . (1990) . Caseicin 80: purification and characterization of new Bacteriocin From Lactobacillus casei Arch. Microbiol. 154:249-252.

8. Gupte, P K.; Mital, B. K. and Garg , S.K.(1996). characterization of Lactobacillus acidophilus strain for use as dietary agjunct. Int. J. of food Microbiology. 29:7-9

9. القصاب، عبد الجبار عمر قوجة. (1988). التأثير المضاد لبكتريا حامض اللبنبك العصوية على .

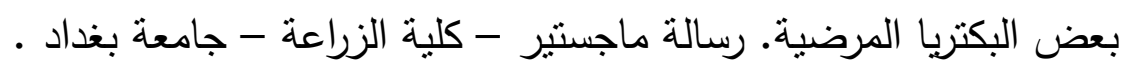

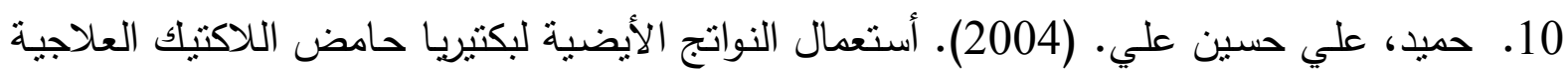
لحفظ منتجي الجبن والقشطة. رسالة ماجستير ـ كلية الزراعة-جامعة بغداد. 